\title{
ELECTROMYOGRAPHIC AND KINETIC STRATEGIES TO CONTROL MOVEMENTS
}

\author{
Marconi NF ${ }^{1,2}$, Almeida GL ${ }^{1,2}$,Gottlieb GL ${ }^{3}$ \\ ${ }^{1}$ Department of Physiology and Biophysics, Institute of Biology, State University of Campinas, Campinas, SP, Brazil \\ ${ }^{2}$ Physical Therapy Course, University of Ribeirão Preto, Ribeirão Preto, SP, Brazil \\ ${ }^{3}$ Motor Control Laboratory, Boston University Supervisor, Neuromuscular Research Center, Boston, USA \\ Corresponding author: Nádia Fernanda Marconi, University of Ribeirão Preto, Physical Therapy Course, Avenida \\ Costábile Romano, 2201,CEP: 14096-900, Ribeirão Preto, SP, Brazil, e-mail: nadia_m_2000@yahoo.com.br
}

Received: 14/07/2005 - Accepted: 23/09/2005

\begin{abstract}
Introduction: This paper is a literature review on the electromyographic and kinetic strategies used by the central nervous system to control voluntary movement. Such strategies have been identified from carrying out simple and complex movements, with and without direction reversal. Objective: To discuss the set of rules used to modulate the muscle activity patterns and muscle torque generated during voluntary movements involving one and two joints. Electromyographic strategies used to control simple movements involving one or two joints are dealt with first. Kinetic strategies are discussed in terms of the generation and modulation of muscle torque to carry out simple and complex movements. Linear synergy between muscle activity and muscle torque and the correlation of the muscle torque generated between chain-linked joints are then discussed. The role of interactive forces in the control of movements is also discussed. Conclusion: Physical therapy practice requires a theoretical framework based on technical-scientific knowledge to guide it. Motor control theories are powerful tools for this. Such knowledge could be used towards understanding the adaptations and modifications in motor control mechanisms that occur as a result of disorders or disease.
\end{abstract}

Key words: movement reconstruction, kinematics, kinetics, EMG, motor control.

\section{RESUMO}

\section{Estratégias Eletromiográficas e Cinéticas para o Controle dos Movimentos}

Introdução: O presente trabalho é uma revisão de literatura sobre as estratégias eletromiográficas e cinéticas usadas pelo sistema nervoso central para controlar movimentos voluntários. Essas estratégias foram identificadas durante a execução de movimentos simples e complexos, com e sem reversão em direção. Objetivo: A proposta desse artigo é discutir o conjunto de regras usadas para modular os padrões de atividade muscular e a força gerada nas articulações (torque muscular). Primeiramente, abordamos as estratégias eletromiográficas usadas para controlar movimentos envolvendo uma ou duas articulações. Discutimos as estratégias cinéticas, em termos de geração e modulação do torque muscular para realizar movimentos simples e complexos. A sinergia linear entre atividade muscular e torque muscular e a correlação entre torque muscular gerado em articulações ligadas em cadeia também será discutida. Além disso, abordamos o papel das forças de interação para o controle dos movimentos. Conclusão: A prática da fisioterapia requer um arcabouço teórico baseado no conhecimento técnico-científico para guiá-la. Nesse sentido, as teorias de controle motor são ferramentas importantes. Tais conhecimentos seriam utilizados para entender as adaptações e modificações que ocorrem nos mecanismos de controle motor devido a uma disfunção ou doença.

Palavras-chave: reconstrução de movimento, cinemática, cinética, EMG, controle motor. 


\section{INTRODUCTION}

Is there a "correct" or best way of making a movement? Neurologically normal (NN) individuals are able to point at a target in space with the same precision, whether the elbow is free or restricted by a splint ${ }^{1}$. This capacity of the nervous system to adapt is due to an infinite combination of movements of the various joints involved in carrying out a motor function. Bernstein ${ }^{2}$ was the first to describe this abundance of movement combinations, which is called the problem of excess degrees of freedom. This makes it possible to carry out the same motor action in numerous ways. If a unique kinematic solution does not exist in terms of the joints and amplitudes of the movements involved in carrying out a motor action, how does the nervous system choose one solution out of many possible alternatives, instead of another?

\section{Electromyographic strategy}

Other motor control models have tried to answer this question by analyzing electromyographic (EMG) patterns while tasks are being performed. These are known as motor control models based on EMG activity ${ }^{3,4,5}$.

These EMG patterns have been studied with both simple (e.g. single-joint, elbow flexion) and more complex movements
When we carry out an elbow extension task, the muscle activation is characterized by the generation of three-phase or two-phase and reciprocal activity pattern (antagonistagonist ${ }^{6,7}$. The arm is extended by activation of the agonist muscles (i.e. triceps), thereby generating a force that is transmitted to the elbow in the form of torque, which accelerates the limb towards the target. This activation is characterized by an abrupt increase in EMG activity (envelope), which starts about 30 milliseconds before limb acceleration and decreases gradually until the end of this acceleration (about halfway through the extension movement). The start of an envelope of activity in the antagonist muscle (i.e. biceps) can be identified a few hundred milliseconds after the start of the agonist onset, which extends beyond the end of the movement. This antagonist envelope decelerates the limb so that it stops at the target. The time between the start of the agonist envelope and the antagonist is called the antagonist latency ${ }^{3,4}$. At the end of the deceleration phase, a second envelope of agonist activity of lower magnitude may be observed. This has the function of locking the limb on the target $^{7}$, thereby avoiding undesirable oscillations of the limb in the final position ${ }^{8}$ (figure 1).

Movements with greater angular amplitude have higher peak velocities. This is because we are more efficient in generating muscle force in wider movements. In other words, for greater distances, we accelerate the limb with more

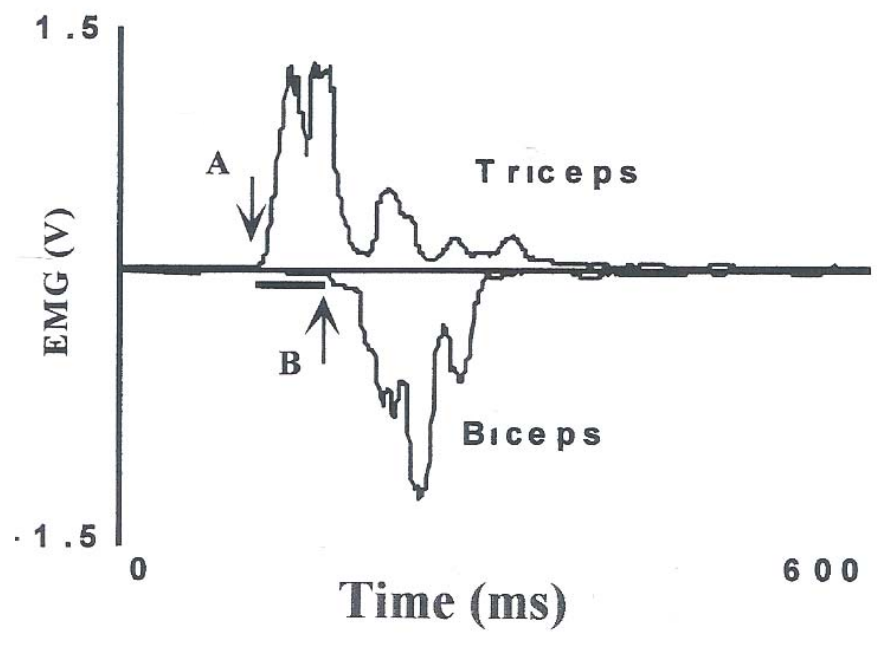

Figure 1. Three-phase pattern of muscle activation in a restricted extension movement of the elbow joint. The electromyographic activities of the brachial triceps (agonist) and brachial biceps (antagonist) muscles are in volts and the time scale in milliseconds. The EMG activity of the brachial biceps is represented in the inverted form. The arrow in A represents the beginning of triceps EMG activity and the arrow in B the beginning of biceps EMG activity. The antagonist latency time can be measured from the difference between A and B (horizontal bar). The data are from our laboratory.

(e.g. reverse movements of the upper limb involving the shoulder and elbow joints). Based on these studies, attempts have been made to identify the rules (strategies) used by the central nervous system (CNS) to generate the appropriate EMG patterns. intensity towards the target, through increasing the quantity of the first agonist envelope, and delay the start of braking, represented by the increase in antagonist latency ${ }^{3}$ (figure 2 on the left). 


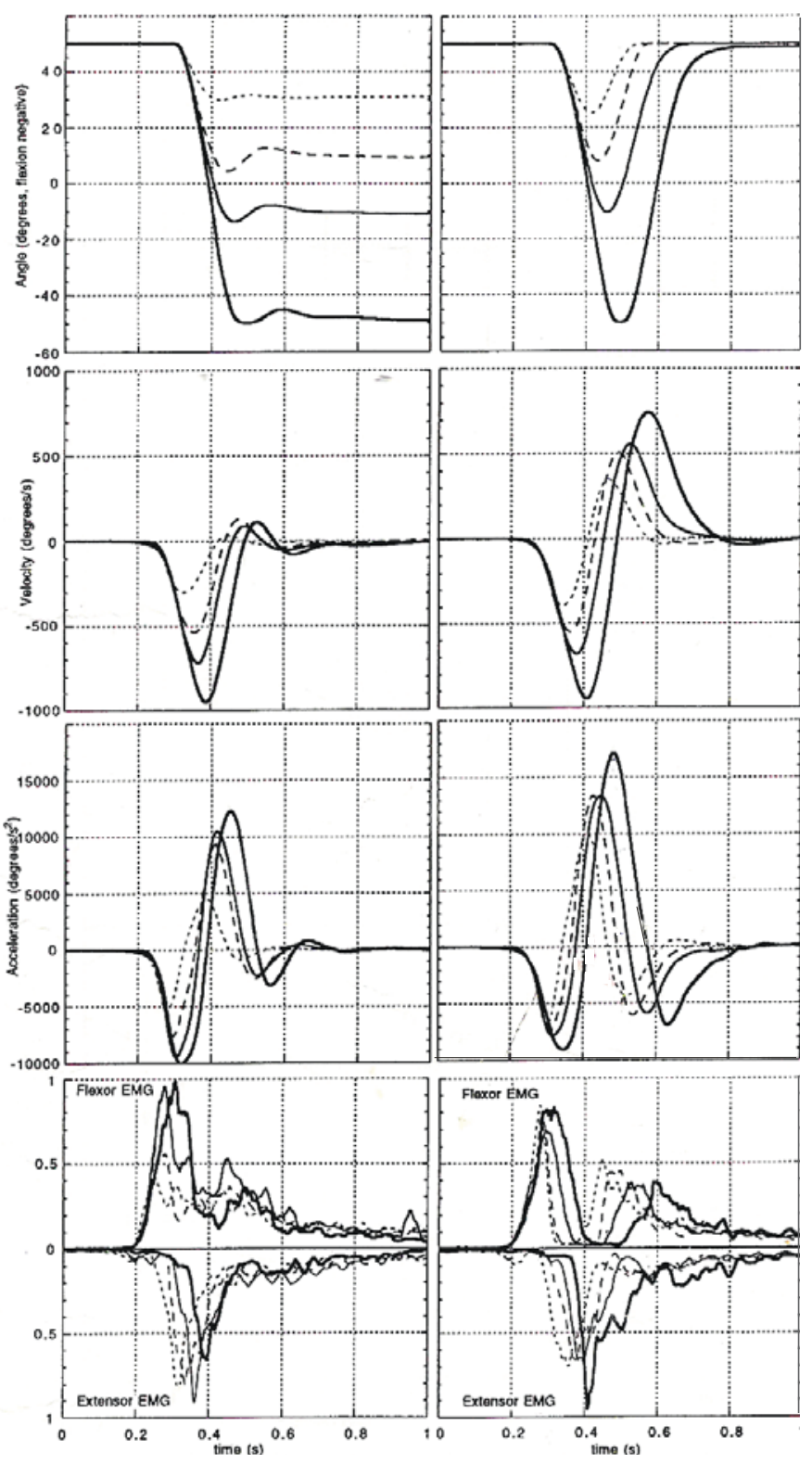

Figure 2. Agonist (brachial biceps) and antagonist (lateral head triceps) angle, velocity, acceleration and EMG activity for aiming movements (on the left) and reversion movements (on the right), in the horizontal plane. The traces represent the average of 10 movements carried out for four different angular distances $\left(20,40,60\right.$ and $100^{\circ}$, respectively, dotted line, broken line, fine continuous line and thick continuous line). The angle is given in degrees, the velocity in degrees per second, the acceleration in degrees per second squared and the time in seconds. The antagonist EMG activity is represented in the inverted form. (From Gottlieb, 1998, permission granted).

In order to modulate the agonist and antagonist activities, the CNS only needs to modulate a small number of parameters in the central commands (action potential envelopes). These are projected onto the alpha motor neurons at the spinal cord level, via descending tracts. In such cases, the alpha motor neurons act as low-pass filters, determining the quantity of motor units in the muscle to be recruited, and prolonging this activation until there is enough muscle activity to accelerate the limb towards the target ${ }^{3}$.

Modulation of the EMG patterns using simple rules has also been observed in movements carried out against the action of gravity, involving the shoulder and elbow joints ${ }^{9}$.

Could this strategy of modulating the EMG activity explain how more complex movements such as reversion are carried out? Gottlieb ${ }^{10}$ showed that elbow reversal movements carried out in a manipulandum were also performed using a three-phase pattern of muscle activity. However, to reverse the movement back to the starting point, the CNS "abruptly" switched off the first envelope of agonist activity at about the end of the limb acceleration phase towards the target. Two clearly separated envelopes of agonist activity were distinguishable (figure 2 on the right). Similar results have been observed by other authors ${ }^{11,12}$.

EMG activity modulation strategies are also present in movements with reversal carried out in the horizontal plane involving the shoulder and elbow joints ${ }^{13,14}$. If, on the one hand, while carrying out aiming movements, the antagonist activity has the function of decelerating the limb so as to come to a halt at the target, in reversion movements this activity has three distinct functions: to decelerate the limb so as to stop at the target, to reverse the direction of movement and to accelerate the limb back to its starting position. In this way, the antagonist envelope acts as an agonist just before the phase of acceleration back to the original position. According to Gottlieb $^{10}$, abruptly switching off the first agonist envelope allows for more efficient action of the antagonist musculature, which has the task of braking the limb at the target, and reversing the direction of movement to bring the limb back to the starting position.

For reversal movements, the quantity of the first agonist envelope and the quantity of the antagonist envelope also increase with the distance of the movements (figure 2 on the right). As a result, we move faster for greater distances when we launch the limb towards a target and when accelerating back to the original position ${ }^{13,14}$.

\section{Kinetic control strategy}

Kinetics is a branch of biomechanics involving the study of force and torque. When a muscle is contracted, a force is generated and this is transmitted to the joint or joints spanned by the muscle in the form of torque. The torque magnitude varies with the distance between the line of action of the force generated by the muscle and the center of the joint. It is assumed that the EMG pattern and amount of activation will be physiologically related to the generation of torque, since the electrical activity of the muscle produces actin-myosin cross-bridges, thereby shortening the length of the sarcomeres and generating muscle force ${ }^{15}$. 
In aiming movements, the muscle torque has a twophase pulse. The first envelope of agonist activity generates the first impulse of muscle torque (the area under the plot of torque versus time), thus accelerating the limb towards the target. About halfway through this movement, this impulse reverses its direction due to activation of the antagonist musculature. In the same way, the envelope of antagonist activity generates a second torque impulse, thereby decelerating the limb at the target (figure 3).

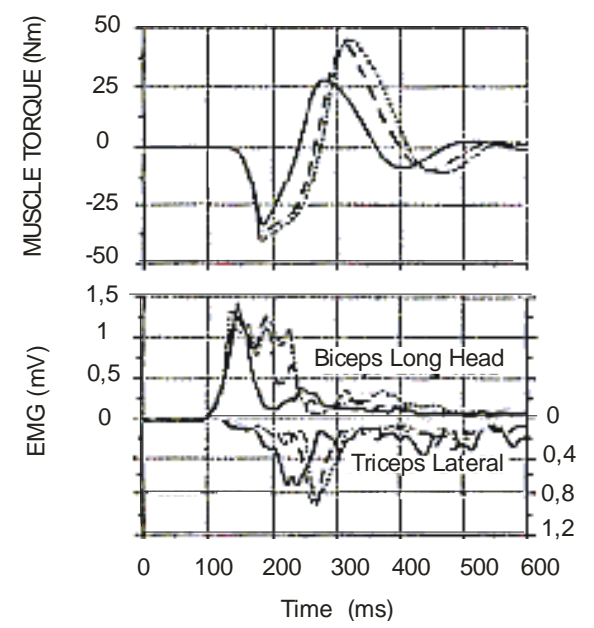

Figure 3. Muscle torque of the elbow and EMG activity of the biceps (agonist) and triceps (antagonist) during restricted flexion movements of the elbow for three different angular distances (25, 50 and $75^{\circ}$, respectively, solid line, broken line and dotted line). The movements were carried out "as quickly as possible". Muscle torque is given in Newton meters, EMG activity in microvolts $(\mathrm{mV})$ and the time in milliseconds (ms). (From Almeida et al., 1995, permission granted).

For reversal movements, the muscle torque profile becomes more complex. In aiming movements, the first impulse is generated by the first envelope of agonist activity. This is responsible for accelerating the limb towards the target (figure 4). The end of this stage coincides with the end of the first acceleration phase (from the starting position to the target). From this moment onwards, the limb starts to decelerate to about the halfway point and the muscle torque reverses its direction for the first time. A second impulse can also be identified, generated by the activity of the antagonist muscle. As mentioned earlier, in reversal movements, the antagonist muscle first stops the limb at the target, and then reverses its direction of movement and accelerates the limb back to the original position. The end of the second impulse coincides with the end of the second phase of limb acceleration (from the target back to the starting position). Finally the muscle torque reverses its direction for the second time. A third impulse can also be identified, generated by the second envelope of muscle activity, acting initially as the agonist. This impulse stops the limb when it is back at the starting position.

In the same way as for agonist EMG activity, muscle torque has also been shown to be modulated with increasing angular distance, for simple constrained ${ }^{3}$ and unconstrained 5,9 movements, and for reversal movements involving the shoulder and elbow joints ${ }^{13,14,16}$. Modulation of muscle torque with the distance moved has been found to occur for both acceleration and deceleration impulses, independent of whether the torque pattern is two-phase or three-phase.

It can thus be concluded that, to carry out movements at greater distances, the CNS generates a greater amount of agonist and antagonist activity and delays the start of the antagonist activity, thereby resulting in a greater acceleration impulse and hence faster movements.

\section{Correlation between EMG activity and muscle torque}

Recently, Marconi ${ }^{13}$ demonstrated that high linear correlation between the envelopes of agonist and antagonist EMG activity can also be observed with regard to muscle torque impulses in the shoulder and elbow, while performing arm reversal movements in the horizontal plane, in different spatial orientations. For example, the first envelope of agonist activity showed high linear correlation with the first acceleration impulse. The end of the agonist EMG activity of the posterior deltoid (shoulder) and lateral triceps (elbow) coincided, in temporal terms, with the first reversal of muscle torque at both joints and with the first linear velocity peak of the fingertip (figure 4). The envelope of antagonist EMG activity demonstrated high correlation with the second impulse of muscle torque. The antagonist EMG activity of the anterior deltoid (shoulder) and the biceps (elbow) approximately coincided with the time interval of the second impulse, which consisted of the first phase of deceleration before the target, the reversal of movement and the second phase of acceleration (back to the starting position). In temporal terms, the end of the second impulse coincided with the second linear velocity peak (figure 4). Finally the second agonist EMG envelope also revealed linear correlation with the third impulse of muscle torque. The second envelope of the posterior deltoid (shoulder) and the triceps (elbow) coincided with the time of the third impulse. This phase coincided with the second deceleration near the starting position (figure 4). This pattern was observed in all the spatial orientations studied. In other words, there is true linear correlation between EMG activity and the generation of muscle torque for complex movements such as reversal.

\section{Correlation between the torque in interconnected joints}

For planar movements without reversal ${ }^{17,18,19}$ and with $^{13,16}$ reversal, the torque generated at the shoulder and elbow joints has been shown to have high correlation. The linear correlation 


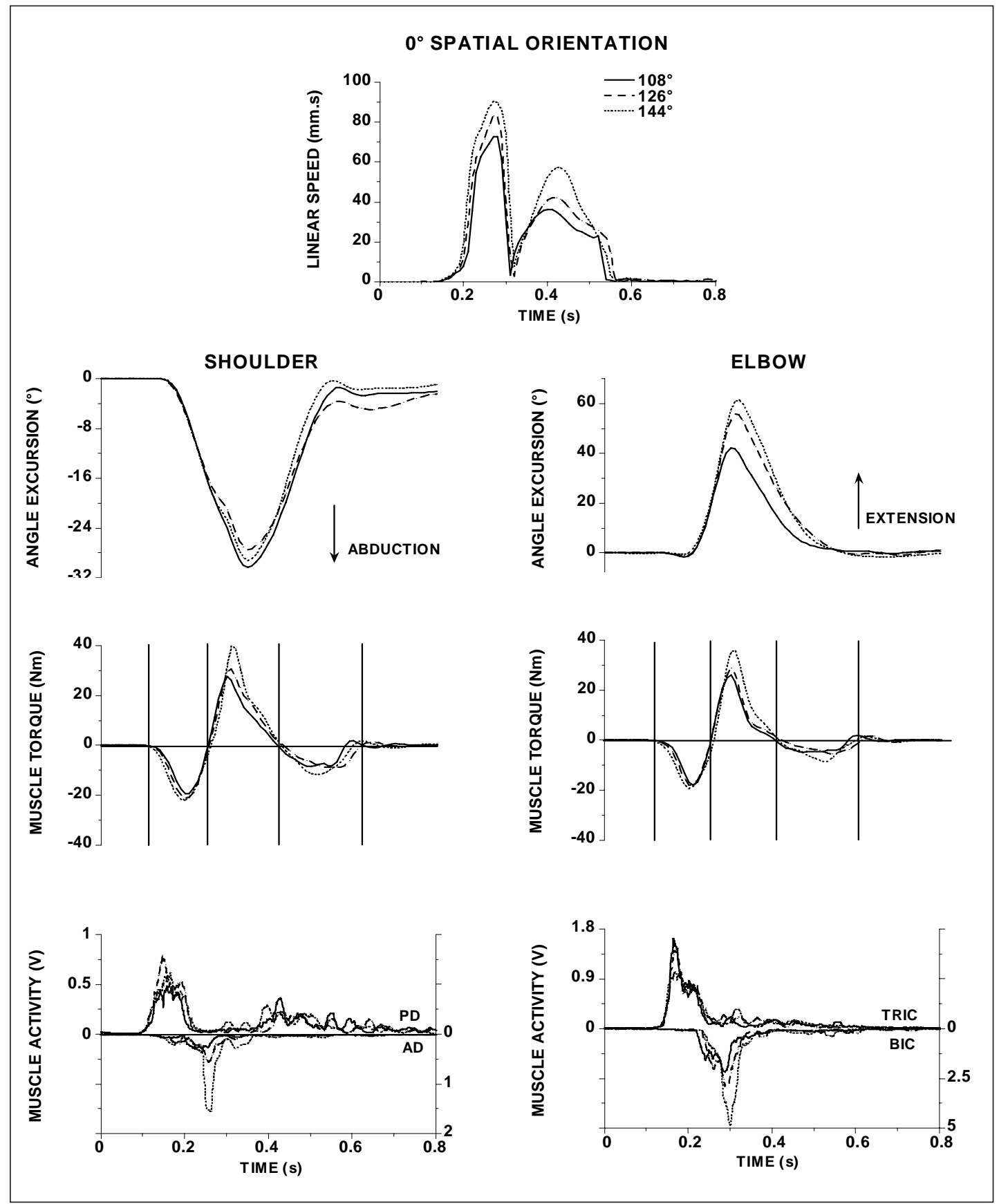

Figure 4. Linear velocity of the index finger (top), joint displacement, muscle torque and EMG activities of the shoulder (left) and elbow (right) joints. The figure illustrates reversion movements for three angular distances ( $108^{\circ}$ - solid line, $126^{\circ}$ - broken line and $144^{\circ}$ - dotted line), in $0^{\circ}$ spatial orientation. The task induced abduction movements of the shoulder joint and extension of the elbow joint. The vertical lines on the muscle torque represent the three muscle impulses, between lines $\mathbf{A}$ and $\mathbf{B}$ (first impulse); between lines $\mathbf{B}$ and $\mathbf{C}$ (second impulse) and between lines $\mathbf{C}$ and $\mathbf{D}$ (third impulse). The lines $\mathbf{B}$ and $\mathbf{C}$ represent the two times at which the muscle torque reversed its direction. The EMG activities illustrated are those of the posterior deltoid (PD) and anterior deltoid (AD) muscles for the shoulder joint, and the lateral triceps (TRIC) and brachial biceps (BIC) for the elbow joint. (From Marconi, 2000, permission granted).

for the muscle torque generated at the two chain-linked joints has been called a "Principle of linear covariance"18. This coupling can be observed for simultaneous change in torque direction and proportional increase and decrease in torque magnitude with time (figure 4). Similar results have been presented in studies on aiming movements in different spatial directions ${ }^{19}$. The linear covariance for muscle torque between two joints appears to be a strategy to reduce the number of variables the CNS needs to control during movements ${ }^{2}$. 
Zaal et al..$^{20}$ investigated whether the principle of linear covariance was a learnt strategy. To address this, they conducted a longitudinal study among infants, collecting data before the infants were able to reach out directly for a toy, using their hands, and immediately after they made the first satisfactory attempt to do this. In the pre-reach phase, the trajectory of the hand was imprecise, the muscle torque presented multiple peaks and the shoulder displacement showed poor coordination with the elbow displacement. When the infants became capable of reaching out directly for an object, there was a significant improvement in the variables studied. The hand trajectory and the joint displacements became more consistent and the muscle torque demonstrated the two-phase pattern that is frequently observed in one-way movements. However, the only variable that failed to change was the linear correlation for muscle torque, which was high both before and after the infants were able to reach out directly for the object. Thus, the authors concluded that the principle of linear covariance was an intrinsic characteristic of the motor control system and independent of the degree of capacity for a given task ${ }^{20}$.

Marconi ${ }^{13}$ tested the linear correlation between muscle torque impulses of the shoulder and elbow while carrying out arm reversion movements in the horizontal plane in different spatial orientations. Using principal component analysis, it was shown that the three muscle torque impulses of the shoulder were correlated with the three muscle torque impulses of the elbow in all the spatial orientations investigated. In addition, there was good linear correlation of muscle torque duration (initial, first and second reversions and final) in the shoulder and elbow, thus demonstrating that the muscle torque generated around chain-linked joints changes direction simultaneously in time. This shows the coordination of the torque generated at the two joints.

\section{Interactive Torque}

Interactive torque around other joints is dependent on movement, i.e. movement in a focal joint. Bernstein ${ }^{2}$ proposed that the motor control system incorporated interactive torque in its motor repertoire, instead of opposing this. Schneider et al. ${ }^{21}$ trained neurologically normal (NN) subjects in a reversion task involving the shoulder and elbow joints in the sagittal plane. For this task, the subjects had to move from a starting position to a target and immediately return to the starting position. Both in the upward and downward movements, the subjects circled a barrier. The total joint torque (muscle torque plus interactive torque) of both joints was calculated in all phases of movement (upward, reversal and downward). This study demonstrated that, in all phases of movement of both joints, training resulted in an increase in total torque and interactive torque. These authors concluded that interactive torque could be incorporated into the mechanical solution for a motor action.
Sainburg \& Kalakanis ${ }^{22}$ showed that in right-handed individuals the shape of the hand trajectory was independent of interactive torque. However the shape of the trajectory of the non-dominant hand was less precise in forecasting the action of interactive torque. These authors characterized this strategy as "coordination between muscle actions with dynamics between the segments and indicating an exact forecast of their interactions". One implicit explanation for this is that greater practice by the dominant hand in everyday activities made the neural representation of the musculoskeletal system and the dynamics between the segments become more refined, thereby generating more precise and coordinated movements by the dominant limb. Thus, coordination between the muscles and external forces could be developed within the first year of life $\mathrm{e}^{20,23,24,25}$.

Studies involving training in a motor task have demonstrated that individuals learn to increase the muscle torque impulses in simple tasks ${ }^{26,27}$ and both muscle and interactive torque impulses during complex movements ${ }^{21}$. On the basis of these studies, the question that is posed is whether the CNS would be able to control muscle and interactive torque independently.

Marconi \& Almeida ${ }^{16}$ trained NN subjects in arm reversal tasks involving the shoulder and elbow joints. The shoulder moved in horizontal adduction and the elbow in extension. The authors chose a task for which the kinetic characteristics had been well described in the literature ${ }^{28,29}$ and which required both muscle and interactive torque to act in the same direction at the shoulder and in opposite directions at the elbow. After extensive training the subjects demonstrated the capacity to control muscle and interactive torque independently. With practice, the arm was accelerated more quickly towards the target because of increased muscle torque at the shoulder (in adduction). The greater acceleration of the shoulder generated greater interactive torque at the elbow joint (in extension), thereby decreasing the need to increase elbow muscle torque to accelerate the joint more quickly. The arm was also decelerated more quickly at the target because of increased muscle torque at the shoulder (in abduction) and consequently greater interactive torque at the elbow (in flexion). The arm was again accelerated rapidly to return to the starting position, because of increased muscle torque at the shoulder (in abduction) and interactive torque at the elbow (in flexion). Finally, the arm was decelerated more quickly at the starting position because of increased muscle torque at the shoulder (in adduction) and interactive torque at the elbow (in extension). The pattern observed over this distance used in training was transferred to other untrained distances.

These authors concluded that the CNS incorporates reactive forces into its repertoire instead of opposing them. These findings corroborate the findings of Bernstein ${ }^{2}$ and Schneider et $\mathrm{al}^{21}$. 


\section{CONCLUSION}

Physical therapy practice requires a theoretical framework based on technical-scientific knowledge to guide it. Motor control theories are powerful tools for this. The present paper has discussed the electromyographic and kinetic strategies used by the CNS to execute simple and complex movements. Such knowledge could be used towards understanding the adaptations and modifications in motor control mechanisms that occur as a result of disorders or disease.

Professionals do not require sophisticated tools to reconstruct movements and register EMG patterns in the clinic or institution where therapy is delivered. Clinical practice must be founded on scientific knowledge such as that described in this literature review. A good example of how such knowledge can be used together with clinical evaluation is offered by Almeida et al. ${ }^{30}$ in their study on the effect of baclofen in reducing spasticity in patients with cerebral palsy.

Acknowledgements: FAPESP (process $n^{\circ}$ 00/10527-6).

\section{REFERENCES}

1. Talis V, Carvalho RL, Jaric S, Almeida GL. Does constraining a redundant degree of freedom affect learning performance. Progress in Motor Control II; 1999 Aug 19-22; Pennsylvania State University, State College.

2. Bernstein NA. The coordination and regulation of movements. Oxford, UK: Pergamon Press, 1967.

3. Gottlieb GL, Corcos DM, Agarwal GC. Organizing principles for single joint movements: I - A speed-insensitive strategy. J Neurophysiol 1989; 62: 342-57.

4. Corcos DM, Gottlieb GL, Agarwal GC. Organizing principles for single joint movements: II - A speed-sensitive strategy. J Neurophysiol 1989; 62: 358-68.

5. Gottlieb GL. On the voluntary movement of compliant (inertialviscoelastic) loads by parcellated control mechanisms. J Neurophysiol 1996; 76:3207-29.

6. Hallett M, Shahani BT, Young RR. EMG analysis of stereotyped voluntary movements in man. Journal of Neurol Neurosurg Psychiatry 1975; 38: 1154-62.

7. Hannaford B, Stark L. Roles of the elements of the triphasic control signal. Exp Neurol 1985; 90: 619-34.

8. Gottlieb GL, Corcos DM, Jaric S, Agarwal GC. Practice improves even the simplest movements. Ex Brain Res 1988; 73: 435-40.

9. Almeida GL, Hong D, Corcos DM, Gottlieb GL. Organizing principles for voluntary movement: extending single-joint rules. J Neurophysiol 1995; 74: 1374-81.

10.Gottlieb GL. Muscle activation patterns during two types of voluntary single-joint movement. J Neurophysiol 1998; 80: 1860-67.
11. Schmidt RA, Sherwood DE, Walter CB. Rapid movements with reversals in direction. I. The control of movement time. Exp Brain Res 1988; 69: 344-54.

12. Sherwood DE, Schmidt RA, Walter CB. Rapid movements with reversals in direction II. Control of movement amplitude and inertial load. Exp Brain Res 1988; 69: 355-67.

13. Marconi NF. Controle motor em indivíduos neurologicamente normais e portadores da Síndrome de Down: O efeito do feedback intrínseco [dissertação]. Campinas (SP): Universidade Estadual de Campinas; 2000.

14. Almeida GL, Freitas SMSF, Marconi NF. Coupling between muscle activities and muscle torques during horizontal-planar arm movements with direction reversal. J Electromyogr Kinesiol. In press 2005.

15. Huxley, AF. Muscle structure and theories of contraction. Prog Biophy Chem 1957; 7: 255-318.

16. Marconi NF, Almeida GL. Principles for learning horizontalplanar arm movements with reversal. J Neurophysiol Submitted 2005.

17.Hong D, Corcos DM, Gottlieb GL. Task dependent patterns of muscle activation at the shoulder and elbow for unconstrained movements. J Neurophysiol 1994; 71: 1261-65.

18. Gottlieb GL, Song Q, Hong D, Almeida GL, Corcos DM. Coordinating movement at two joints: a principle of linear covariance. J Neurophysiol 1996; 75: 1760-64.

19. Gottlieb GL, Song Q, Almeida GL, Hong DA, Corcos DM. Directional control of planar human arm movement. J Neurophysiol 1997; 78: 2985-98.

20.Zaal FTJM, Daigle K, Gottlieb GL, Thelen E. An unlearned principle for controlling natural movements. J Neurophysiol 1999; 82: 255-59.

21.Schneider K, Zernicke RF, Schmidt RA, Hart TJ. Changes in limb dynamics during the practice of rapid arm movements. J Biomech 1989; 22: 805-17.

22.Sainburg RL, Kalakanis D. Differences in control of limb dynamics during dominant and nondominant arm reaching. J Neurophysiol 2000; 83: 2661-75.

23.Thelen E, Corbetta D, Kamm K, Spencer JP, Schneider K, Zernicke RF. The transition to reaching: mapping intention and intrinsic dynamics. Child Dev 1993; 64: 1058-98.

24.Thelen E, Corbetta D, Spencer JP. Development of reaching during the first year: role of movement speed. J Exp Psychol Hum Percept Perform 1996; 22: 1059-76.

25.Zernicke RF, Schneider K. Biomechanics and developmental neuromotor control. Child Dev 1993; 64: 982-1004.

26. Corcos DM, Jaric S, Agarwal GC, Gottlieb GL. Principles for learning single-joint movements I. Enhanced performance by practice. Ex Brain Res 1993; 94: 499-513.

27.Jaric S, Corcos DM, Agarwal GC, Gottlieb GL. Principles for learning single-joint movements II. Generalizing a learned behavior. Ex Brain Res 1993; 94: 514-21.

28. Hollerbach JM, Flash T. Dynamic interactions between limb segments during planar arm movement. Biol Cybern 1982; 44: 67-77. 
25. Zernicke RF, Schneider K. Biomechanics and developmental neuromotor control. Child Dev 1993; 64: 982-1004.

26. Corcos DM, Jaric S, Agarwal GC, Gottlieb GL. Principles for learning single-joint movements I. Enhanced performance by practice. Ex Brain Res 1993; 94: 499-513.

27. Jaric S, Corcos DM, Agarwal GC, Gottlieb GL. Principles for learning single-joint movements II. Generalizing a learned behavior. Ex Brain Res 1993; 94: 514-21.

28. Hollerbach JM and Flash T. Dynamic interactions between limb segments during planar arm movement. Biol Cybern 1982; 44: 67-77.

29. Almeida GL, Hasan Z, and Corcos DM. Horizontal-plane arm movements with direction reversals performed by normal individuals and individuals with Down syndrome. J Neurophysiol 2000; 84: 1949-1960.

30. Almeida GL, Campbell SK, Girolami GL, Penn RD, Corcos DM. Multidimensional assessment of motor function in a child with cerebral palsy following intrathecal administration of baclofen. Phys Ther 1997; 77: 751-64. 